\title{
Parâmetros Acústicos de Perguntas SiM-NÃo E WH - NO ALEMÃo E NO PORTUGUÊS BRASILEIRO
}

\section{Acoustic Parameters in German and Brazilian Portuguese Question Intonation}

\author{
Katja Reinecke*
}

\section{INTRODUÇÃO}

Neste trabalho apresentamos os resultados de uma análise acústica de parâmetros prosódicos em sentenças interrogativas no alemão (doravante $\mathrm{AL}$ ) e no português brasileiro (PB). O objetivo dessa pesquisa é a comparação de perguntas sim-não e perguntas Wh- nos dois idiomas e a descrição dos seus padrões prosódicos. São considerados os valores de frequência fundamental, intensidade e duração. A questão norteadora da avaliação diz respeito à aplicação destes parâmetros acústicos: eles servem para realizar funções semelhantes em línguas diferentes?

O trabalho se divide em duas partes. A primeira considera a descrição formal dos aspectos prosódicos encontrados nos dados de fala. Na segunda parte, são avaliadas as funções linguísticas dos parâmetros acústicos analisados anteriormente.

A análise se baseia nas gravações de doze sentenças interrogativas (seis exemplos de pergunta sim-não e seis de pergunta Wh-) em cada língua, lidas por dois falantes nativos do PB e dois falantes nativos do AL, de sexo masculino, usando um total de 47 sentenças ${ }^{1}$. Os parâmetros foram analisados acústica - e auditivamente, usando o programa Praat ${ }^{2}$ para a avaliação acústica.

\footnotetext{
UFPR

Dos 48 arquivos de som originais, um foi posteriormente corrompido, não podendo mais ser analisado para este trabalho.

Sistema de análise fonética, desenvolvido por Paul Boersma e David Weenink do Departamento de Ciência Fonética da Universidade de Amsterdam.
} 
ReinecKe, K. ParÂmetros Acústicos de Perguntas Sim-Não e Wh...

Ambos os tipos de interrogativa, as perguntas sim-não e as perguntas Wh-, mostram um padrão prosódico específico em cada língua. Os informantes foram solicitados a ler as sentenças de maneira mais natural e neutra possível. Os padrões descritos neste trabalho, portanto, retratam a prosódia de leitura.

\section{OBJETIVO}

O objetivo deste trabalho é a comparação dos padrões prosódicos de interrogativas formados pelos parâmetros frequência fundamental (F0), intensidade e duração em duas línguas diferentes, o AL e o PB. Esses três parâmetros acústicos são considerados, ao lado das características espectrais, os principais meios de sinalização prosódica. Os aspectos prosódicos de interrogativas são interessantes por dois motivos. Primeiro, a sinalização do modo parece uma das primeiras funções da prosódia: "[...] the most uncontroversial function[s] of intonation is that of conveying different illocutionary aspects, or modes." (HIRST; DI CRISTO, 1998, p. 24, negrito no original). Segundo, parece que a prosódia das interrogativas permite a comparação universal entre diversas línguas. Alguns fenômenos, como certas formas de elevação da curva entoacional, do pitch $^{3}$, são observados universalmente como características do modo interrogativo. A análise da relação entre função linguística e forma acústica realizada nestes dois idiomas que pertencem à mesma família indo-europeia de línguas - mas a dois subsistemas distintos, o romano e o germânico - revelará os aspectos mais semelhantes e outros, distintos, em ambas as línguas.

\section{EMBASAMENTO TEÓRICO}

\subsection{Definição dos Termos "EnTOAÇÃo" E "Prosódia"}

A sinalização do modo interrogativo, nas línguas do mundo, geralmente é analisada em termos de entoação. O uso dos termos "prosódia" e "entoação", neste trabalho, segue a definição de Hirst e di Cristo (1998), porém, com pequenas modificações no uso dos termos. "Prosódia" para os autores, é o conceito amplo que abrange tanto o sistema abstrato cognitivo da língua, quanto os parâmetros físicos. "Entoação" é usado em dois sentidos. No sentido restrito ("intonation proper") "entoação" denomina a

\footnotetext{
"Strictly speaking, FO is a physical property and pitch is its psychophysical correlate, but in many contexts outside psychophysics little ambiguity arises if the terms are used interchangeably [...]." (LADD, 1996, p. 7)
} 
curva entoacional, o movimento da FO, cujo correlato perceptual é o pitch. No sentido mais amplo, "entoação" é usado para o conjunto dos aspectos linguísticos que resultam do mapeamento dos parâmetros físicos FO, intensidade, duração e características espectrais. Neste trabalho, "entoação" somente será usado no sentido restrito como "curva entoacional". Para a melhor compreensão da terminologia, vale ressaltar o fato de os parâmetros acústicos não se relacionarem biunivocamente aos conceitos linguísticos, merece atenção. Vejamos a relação proposta pelos autores:

\begin{tabular}{|l|l|l|}
\hline $\begin{array}{l}\text { cognitivo } \\
\text { (fonológico) }\end{array}$ & $\begin{array}{l}\text { físico } \\
\text { (acústico) }\end{array}$ \\
prosódia lexical & \\
- acento (stress) & parâmetros prosódicos \\
- tom & quantidade \\
prosódia não-lexical \\
entoação própria- \\
mente dito (pitch)
\end{tabular}

GRÁFICO 1 - Definição dos termos "entoação" e "prosódia"

FONTE: Adaptado de HIRST e DI CRISTO (1998, p. 7, tradução da autora).

\subsection{Algumas Características da Fonologia Prosódica}

A fonologia prosódica está relacionada ao significado pós-lexical, ou seja, atua no nível sentencial. Ladd (1996, p.8) menciona dois aspectos básicos do funcionamento da fonologia prosódica: "Tune" (curva melódica ou da entoação) e "Relative Prominence" (proeminência relativa). Tune referese a um movimento básico do pitch: a sílaba tônica de um determinado item lexical pode possuir um valor de FO mais alto (high) ou mais baixo (low) do que as sílabas tônicas do itens lexicais vizinhos. Relative Prominence refere-se a um conceito de que a sílaba tônica de um item lexical pode ser ou mais salientado (strong) ou menos salientado (weak) do que as sílabas tônicas de outros itens lexicais em comparação. Esses dois conceitos combinados permitem quatro possíveis relações: 
Reinecke, K. ParÂmetros Acústicos de Perguntas Sim-NÃo e Wh..

$$
\begin{aligned}
& \text { 1) } \begin{array}{l}
\text { high - low } \\
\text { weak-strong }
\end{array} \\
& \text { 2) } \quad \begin{array}{l}
\text { high - low } \\
\text { strong - weak }
\end{array} \\
& \text { 3) low - high } \\
& \text { weak - strong } \\
& \text { low - high } \\
& \text { strong - weak }
\end{aligned}
$$

O conceito tune é relacionado à $\mathrm{FO}$, o conceito relative prominence à intensidade e à duração. Ambos os conceitos se aplicam às línguas em geral. Maddieson (1997) observa outras características universais como o alongamento final e a declinação entoacional geral. Esses dois fenômenos são importantes para este trabalho, porque influenciam os resultados acústicos avaliados. $\mathrm{O}$ alongamento final (phrase-final and word-final lengthening progresses) serve para a demarcação final de constituintes prosódicos. Alem de sinalizar uma fronteira frasal, o alongamento também demarca informações fornecidas por mudanças na qualidade da voz ou da entoação, por exemplo. $O$ alongamento final não acontece necessariamente na última sílaba do constituinte propriamente dito. Ele pode ocorrer antes. Nos exemplos avaliados para este trabalho, observamos um comportamento bem regular de aumento de duração nas sílabas finais das sentenças, em ambas as línguas.

Um outro fenômeno universal importante de se levar em consideração para poder avaliar o pitch é a declinação entoacional geral. Maddieson (1997, p. 632) afirma "[...] declination is, broadly speaking, associated with the baseline decline in the subglottal pressure that occurs as lung volume decreases over the course of an utterance." Para este trabalho, é importante conhecer o efeito da declinação entoacional, para avaliar a proeminência relativa de picos de pitch. Uma elevação entoacional no final de uma sentença atinge um nível tonal relativamente mais baixo do que uma elevação no início da sentença. Em termos de percepção, porém, até um pico com um valor físico inferior pode parecer ser o mais alto, se ele for realizado no final da sentença. Como a declinação é fisicamente bastante complexa, não pretendemos calcular o seu exato efeito nas sentenças gravadas. Mas é necessário se levar em consideração a proeminência relativa

LADD (1996, p. 8). 
ReinecKe, K. ParÂmetros Acústicos de Perguntas Sim-Não e Wh...

de movimentos de pitch que ocorrem mais próximos ao final de uma sentença.

\subsection{A Prosódia de InTERrogativas EM AL E No PB}

\subsubsection{MORAES (1998) SOBRE InTERROGATIVAS NO PB}

No PB, como na maioria das línguas conhecidas, a curva entoacional se abaixa no final de uma asserção não-enfática. Depois de um pitch inicial médio, a melodia se abaixa na última sílaba tônica. Em enunciados maiores, o autor observa uma declinação geral desde a primeira sílaba, até a última. Para a sinalização do modo interrogativo, Moraes constata que no PB a entoação é o meio primário de sinalizar o modo interrogativo, embora a ordem sintática contribua. Para contrastar com o modo declarativo, os diferentes tipos de pergunta são marcadas por elevações do pitch em certas sílabas. Nas perguntas sim-não, a elevação do pitch acontece na última sílaba tônica da sentença. Em perguntas Wh-, a elevação do pitch acontece na primeira sílaba tônica da sentença. Em construções sintáticas em que o pronome interrogativo ocupa a última posição sintática, a elevação do pitch ocorre na sílaba tônica antes do pronome interrogativo.

Um padrão destacado pelo autor é o movimento entoacional de duas elevações. Este, segundo Moraes, é usado em ocasiões como a iniciação de um diálogo. Neste caso, a sentença inteira é tratada como informação nova, o seu escopo informacional amplo é refletido por mais do que uma saliência através do pitch. Moraes descreve o padrão da seguinte forma: a elevação principal e maior acontece na primeira sílaba tônica da sentença, e a segunda elevação na última sílaba tônica. No exemplo dado pelo autor, vê-se uma ascensão, imediatamente seguida por uma descida do pitch, dentro da última sílaba.

\section{SeRÁ que vai choVER?

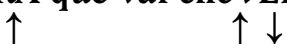

3.3.2. STOCK (1996) SOBRE INTERROGATIVAS NO AL

Vejamos inicialmente alguns detalhes da estrutura sintática. O AL é uma língua V2, com inversão sintática nas perguntas sim-não. Isso significa que, nesse tipo de perguntas, o verbo ocupa obrigatoriamente a primeira posição, seguido pelo sujeito gramatical. Porém, através da entoação, é possível transformar uma sentença de ordem sintática declarativa em uma 
ReinecKe, K. ParÂmetros Acústicos de Perguntas Sim-Não e Wh...

pergunta sim-não e vice-versa. Stock (1996) constata a existência de sentenças que sintaticamente são perguntas sim-não, mas sem serem sinalizadas através da entoação. Realizar a inversão sintática e a entoação típica de pergunta sim-não, portanto, parece uma redundância da língua na sinalização do modo.

Ao contrário do que Moraes (1998) constata para o PB, Stock (1996) afirma que, no AL, a importância da entoação para a sinalização do modo de uma sentença é menor do que se acredita em geral. Na fala espontânea, segundo o autor, são usados outros meios linguísticos, estando em primeiro lugar a sintaxe para marcar um enunciado como interrogativo. Para Stock, no sinal entoacional, atuam várias influências diferentes que encobrem a sua função de sinalizar o modo. Essas influências são marcadores regionais e dialetais, marcadores da atitude do falante e de ênfases e marcadores da estrutura informacional ${ }^{5}$. Contudo, Stock conclui que, salvo certas construções sintáticas, a realização prosódica de interrogativas no AL é relativamente livre.

Enquanto Moraes (1998) descreve a entoação interrogativa do PB a partir de elevações do pitch em diferentes lugares da sentença (no começo ou no final), Stock mostra, para o AL, que o movimento decisivo do pitch acontece somente no final da sentença. Perguntas sim-não são sinalizadas, normalmente, com uma ascensão entoacional no final e perguntas Wh-com uma curva decrescente no final. É importante observar que Moraes, que também fala de elevações do pitch, se refere a elevações seguidas por uma descida entoacional. No AL, nas perguntas sim-não, a curva entoacional sobe no final da sentença, sem descer. Stock tenta caracterizar alguns tipos de perguntas que exigem mais rigidamente a entoação interrogativa padrão. Se a construção sintática é inequivocadamente interrogativa, pode não ocorrer a entoação padrão. A colocação de certas partículas pode eliminar a ambiguidade do modo de uma sentença. Ao contrário, perguntas sem inversão sintática e construções sintáticas elípticas exigem a aplicação do padrão entoacional.

\section{Procedimento Metodológico}

\subsection{OS INFORMANTES E O MATERIAL PARA AS GRAVAÇÕES}

As sentenças para as gravações foram escolhidas considerando-se os seguintes critérios: para cada língua, foram selecionados doze exemplos,

\footnotetext{
A informação nova (o rema) tende a ser colocada no final da sentença e é salientada por diferentes meios acústicos.
} 
seis para cada tipo de pergunta. Todas as sentenças contêm aproximadamente de dez a onze sílabas. Permitindo aos informantes que falassem com a sua velocidade e seu hábito de fala naturais, o número de sílabas realizadas varia conforme de sua junção na realização individual. Para cada tipo de pergunta há sempre dois exemplos que terminam em uma palavra oxítona, paroxítona e proparoxítona. Os verbetes que se encontram na posição final de sílaba são os mesmos seis para as perguntas sim-não e as perguntas Wh-. Cada sentença foi lida três vezes em sequência, para se poder escolher a realização mais balanceada e neutra ${ }^{6}$. Essa foi, salvo poucas exceções, normalmente a realização do meio.

Os informantes são dois falantes nativos de cada língua, de sexo masculino, na faixa etária de 20 a 40 anos. Os informantes brasileiros são da região Sul e Sudeste do Brasil. Os alemães são do Sul da Alemanha. Nenhum deles apresenta particularidades articulatórias desviantes. Todos participaram das gravações como voluntários. As gravações foram realizadas com o $\mathrm{CSL}^{7}$, e depois passados para o formato analisado no Praat.

\subsection{A ANÁLISE}

A análise foi realizada com o programa Praat, considerando os parâmetros FO (Hz), duração (ms) e intensidade (dB). De cada gravação, verificaram-se os valores médios de todas as sílabas e determinaram-se as localizações dos valores máximos para cada parâmetro na sentença toda.

As sílabas que carregam o pico de pitch, ou o máximo de intensidade ou de duração foram descritas segundo a sua posição na sentença e a sua função sintática, pragmática e / ou fonológica, comparando seu valor com a média de toda sentença. Os valores médios e máximos de intensidade e pitch foram calculados pelo próprio programa Praat. Para os valores de duração foram considerados os valores das vogais. A delimitação da duração das vogais é uma tarefa complexa. Consideraram-se então os formantes, a onda, o espectograma e a avaliação auditiva para medir a duração e detectar a vogal mais longa de cada gravação. Em cada fronteira de vogal, admitia-

\footnotetext{
Prosseguindo assim, admitimos um certo efeito de memorização da sentença a ser pronunciada. No âmbito da entoação lida, não-espontânea, preferimos essa opção metodológica antes de uma leitura em ordem aleatória para evitar que os informantes realizassem contornos mais fortes-, e talvez até artificialmente, enfatizados, devido à falta de costume com esse tipo de exercício.

Computerized Speech Lab, modelo 43008, da KAY ELEMETRICS. Em vez de passar de um programa para outro, esse software também teria servido para realizar a análise dos dados, porém, o computador no qual é instalado o programa, não estava permanentemente à disposição durante a elaboração deste artigo.
} 
ReinecKe, K. ParÂmetros Acústicos de Perguntas Sim-Não e Wh...

se uma margem de erro de até $2 \mathrm{~ms}^{8}$. Em 44 casos, a diferença entre a vogal mais longa e a segunda mais longa, foi maior de $9 \mathrm{~ms}$, ou seja, a margem de erro não foi alcançada ${ }^{9}$. Nos 3 casos restantes, a diferença entre a vogal mais longa e a segunda mais longa da sentença em questão, foi de $7 \mathrm{~ms}$ (dois casos) e $6 \mathrm{~ms}$ (um caso).

\subsection{APRESENTAÇÃo dos DADOS}

Em seguida, serão descritos os padrões prosódicos encontrados nos dois tipos de interrogativa nas duas línguas. Inicia-se pelos aspectos formais, abordando, para cada língua e cada tipo de pergunta, as três formas de saliência: pitch, intensidade e duração. Na parte formal, as sílabas são identificadas por sua posição numérica na sentença. Como os exemplos gravados contêm, no máximo, onze sílabas, poderiam ter sido usados os números de 1 a 11. Porém, se observou que, salvo raras exceções, os eventos acústicos observados acontecem quase sempre ou em uma das primeiras cinco, ou em uma das últimas três sílabas. Portanto, a numeração segue a lógica seguinte. Da primeira até a sexta, as sílabas recebem os números de 1 a 6. As últimas três sílabas são chamadas de "a", "p" e "u" (antepenúltima, penúltima e última, respectivamente). No primeiro exemplo, que reflete $o$ maior pitch no AL nas perguntas sim-não, apresentaremos uma tabela com os valores e um gráfico, mostrando os mesmo números, para que o leitor possa comparar o modelo de visualização gráfica com a apresentação "pura" dos dados. Nos exemplos seguintes, aparecerá somente o gráfico.

O número total de exemplos em cada língua é doze para cada tipo de pergunta (seis sentenças, lidas por dois informantes). No caso das perguntas Wh-, tem-se onze exemplos.

Na parte funcional, quando algum evento acústico é ligado a um constituinte sintático, entende-se que é a sílaba tônica desse constituinte que é salientada. Também na parte da análise funcional, será feita uma distinção entre sintaxe, pragmática e fonologia. Na aplicação de valores prosódicos, as três categorias não excluem necessariamente uma a outra. Uma sílaba pode ser salientada por motivos sintáticos, pragmáticos e fonológicos ao mesmo tempo. O uso dos três termos se justifica da maneira seguinte: Qual dos três âmbitos explica melhor o fenômeno? É a sintaxe que influencia a aplicação de valores acústicos? É alguma ênfase pragmática? Ou é uma função

\footnotetext{
Esse valor, de $2 \mathrm{~ms}$, é o resultado do próprio trabalho analítico: Não havia casos em que a dúvida sobre a exata delimitação da vogal abrangesse uma margem maior do que $2 \mathrm{~ms}$. dão um total de $8 \mathrm{~ms}$ de margem de erro.

Já que $2 \mathrm{~ms}$ em cada fronteira (inicial e final) de duas vogais em comparação
} 
fonológica, como observamos para o AL, na saliência da última sílaba da sentença? Mesmo assim, a interpretação funcional é entendida como uma primeira aproximação ao fenômeno, e a categorização sintaxe/pragmática/ fonologia se entende como a indicação a uma direção, não como terminologia fundamental.

\section{APRESENTAÇÃo dos RESULTADOS}

\subsection{ASPECTOS FORMAIS}

\subsubsection{Perguntas Sim-Não}

Os informantes realizavam uma curva entoacional com duas elevações em $75 \%$ dos casos em ambas as línguas. Porém, a forma típica varia entre ambos os idiomas. No $\mathrm{PB}$, as duas elevações são parecidas $\mathrm{e}$ formam dois meio-círculos. A curva começa subindo no início da sentença, alcançando o seu primeiro pico na segunda ou na terceira sílaba da frase. Depois desce, e sobe mais uma vez com um segundo pico em uma das três últimas sílabas, normalmente a tônica. No final a curva desce. Tanto o primeiro, quanto o segundo pico pode ser o maior.

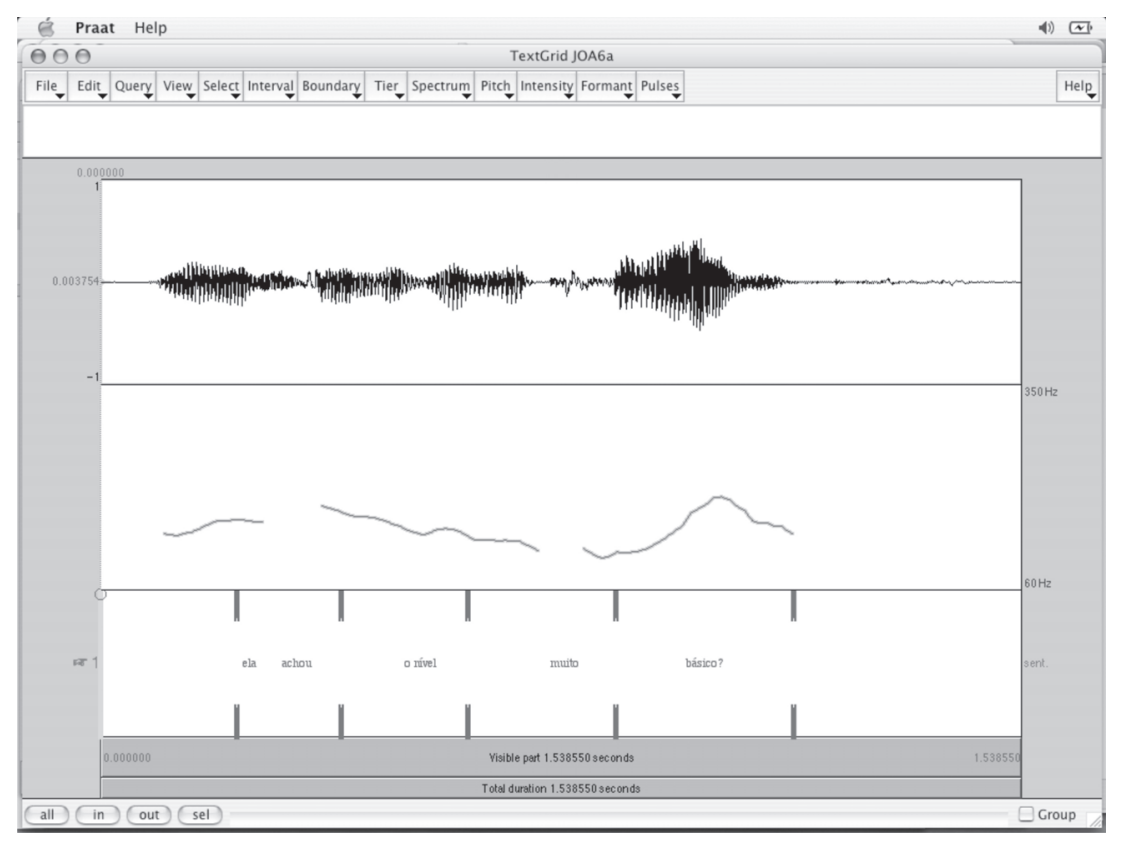

GRÁFICO 2 - Forma típica de perguntas sim-não no PB. Exemplo 1: "Ela achou o nível muito básico?" 
ReinecKe, K. ParÂmetros Acústicos de Perguntas Sim-Não e Wh...

No AL, a primeira elevação normalmente é menos aguda, e forma um meio círculo bem amplo, se estendendo desde a primeira sílaba até dois terços da sentença. Ela é seguida por uma segunda elevação, a mais alta, que termina em movimento ascendente e não completa o meio-círculo. Assim, no $\mathrm{AL}$, todos os exemplos têm o seu pico de pitch maior na última sílaba.

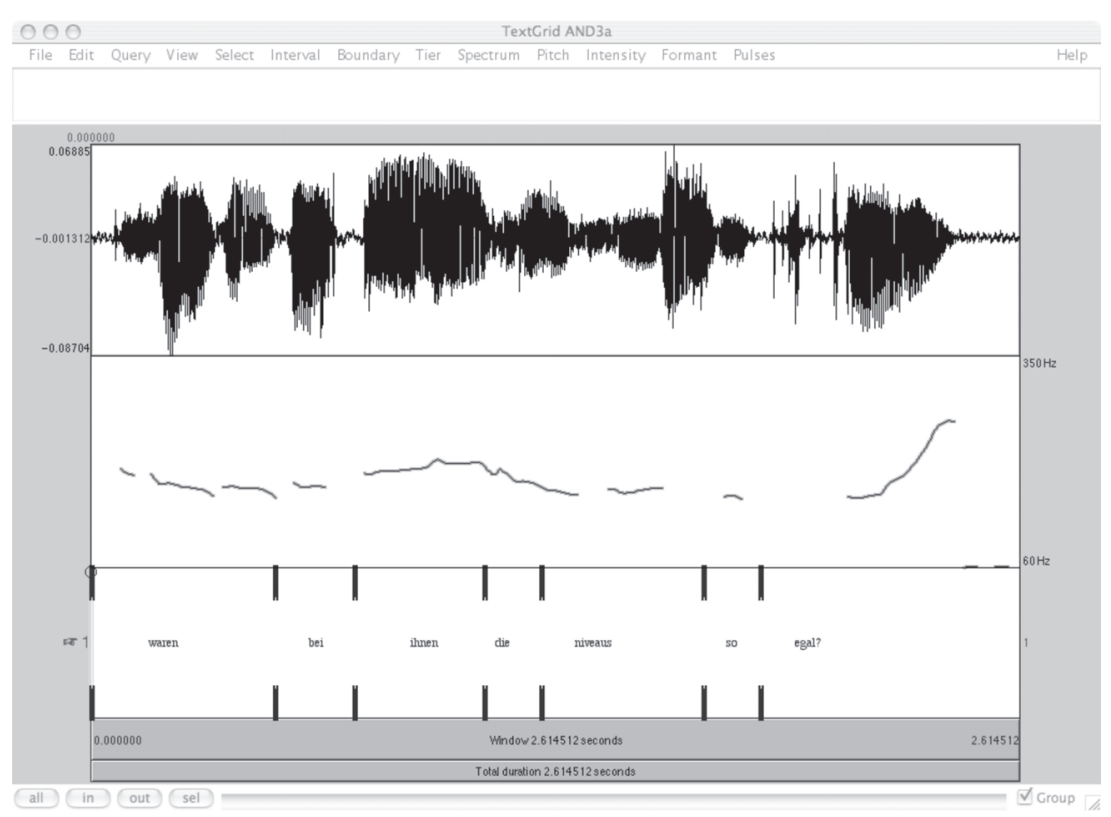

GRÁFICO 3 - Forma típica de pergunta sim-não no AL. Exemplo 2: "Waren bei Ihnen die Niveaus so egal?"

Em números, o maior pico de pitch se distribui da seguinte maneira nos dois idiomas:

\begin{tabular}{|c|c|c|c|c|c|c|}
\hline \multicolumn{2}{|c|}{ máx. pitch } & 2a síl. & 3a síl. & a. síl. & p. síl. & u. síl. \\
\hline \multirow{2}{*}{$\begin{array}{c}\text { No. de } \\
\text { ocorrências }\end{array}$} & AL & - & - & - & - & 12 \\
\cline { 2 - 7 } & PB & 5 & 1 & 3 & 1 & 2 \\
\hline
\end{tabular}

QUADRO 1 - Distribuição dos maiores pico de pitch pelas sílabas nas sentenças no AL e no PB. 
Vejamos, como a mesma informação aparece no gráfico 4:

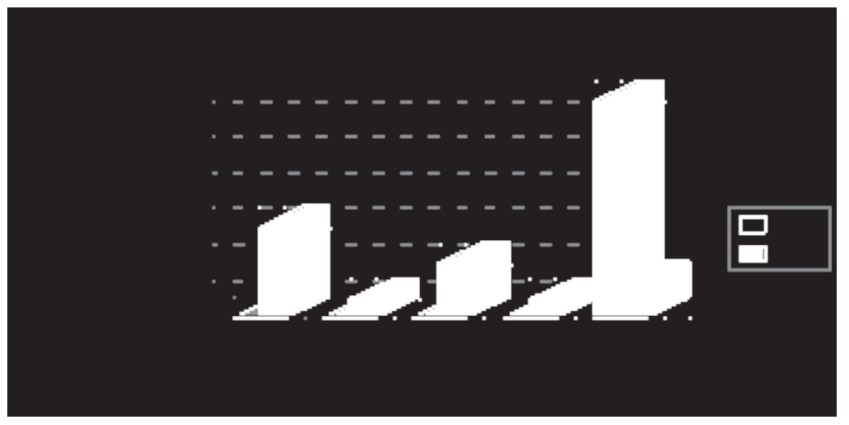

GRÁFICO 4 - Pergunta sim-não no AL e no PB: número de ocorrência dos maiores pico de pitch.

Vemos, então, que no AL predomina um padrão entoacional, que não ocorre no PB. Independentemente da sílaba tônica, o maior pitch fica na última sílaba da sentença. No PB, não parece ser distintivo, se o maior pico do pitch ocorre na primeira, ou na segunda elevação. O segundo pico da sentença recai sobre a última sílaba tônica e não sobre a última da sentença.

Olhando, agora, as sílabas que carregam os valores máximos de intensidade da sentença, não se identifica um padrão tão nítido quanto o do pitch.

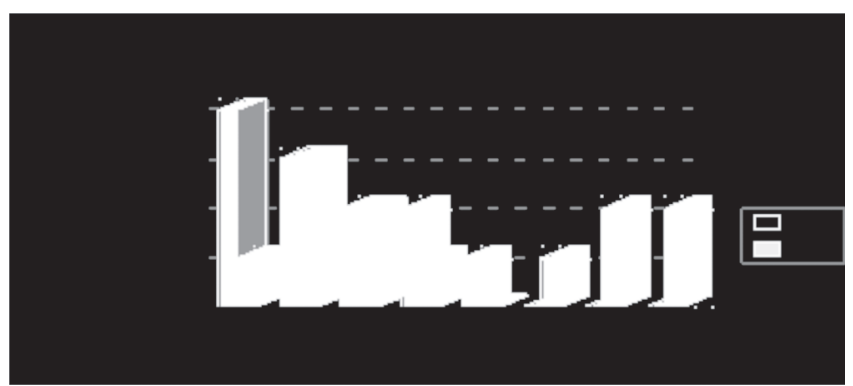

GRÁFICO 5 - Perguntas sim-não no AL e no PB: valores máximos de intensidade

No AL, a tendência é a primeira ou a segunda sílaba carregar o valor máximo de intensidade, porém, este pode recair também na terceira, quarta ou quinta sílabas. Não se observa nenhum caso em que uma das últimas três sílabas, ou, então, a última sílaba tônica carregue o máximo de intensidade. No PB, o máximo de intensidade pode incidir com sete posições diferentes, tanto no começo, como no final da sentença. 
ReinecKe, K. ParÂmetros Acústicos de Perguntas Sim-Não e Wh...

Vejamos a distribuição das sílabas com a maior duração no AL e no PB:

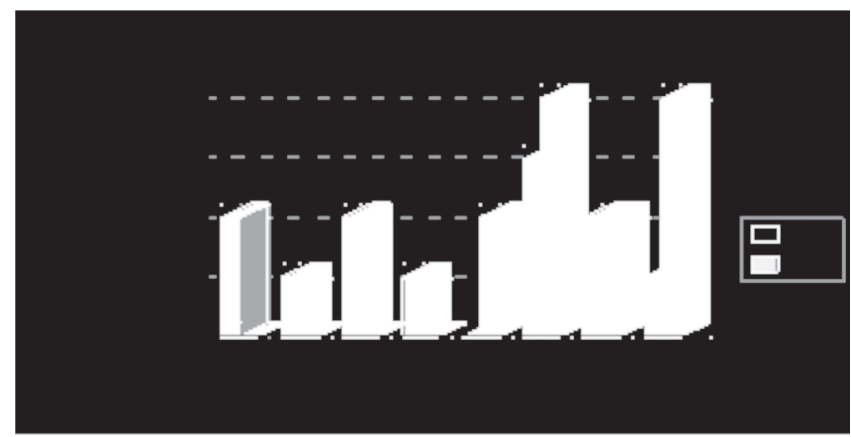

GRÁFICO 6 - Perguntas sim-não no AL e no PB: valores máximos de duração

Neste parâmetro acústico, observamos uma tendência do PB atribuir a maior duração em uma das últimas três sílabas. Somente dois exemplos de doze escapam desse padrão. Na parte funcional, analisaremos possíveis motivos para esses dois casos desviarem do padrão. Já, no AL, no caso da duração, não se apresenta um padrão tão bem definido como o do pitch. Existem sete posições diferentes na sentença, nas quais ocorre a sílaba com a maior duração, podendo estar tanto no começo da sentença, quanto no seu final.

\subsubsection{Perguntas Wh-}

No caso das perguntas Wh-, também se observa um padrão bem definido do parâmetro pitch. No PB, todos os exemplos são realizados com um único movimento de elevação no início da sentença. A tendência é alcançar o seu pico na segunda sílaba (ou, com menos exemplos na primeira ou na terceira) para depois continuar descendo até o final da sentença. Vejamos os exemplos 3 e 4. 
REINECKE, K. ParÂmetros Acústicos de Perguntas Sim-Não e Wh...

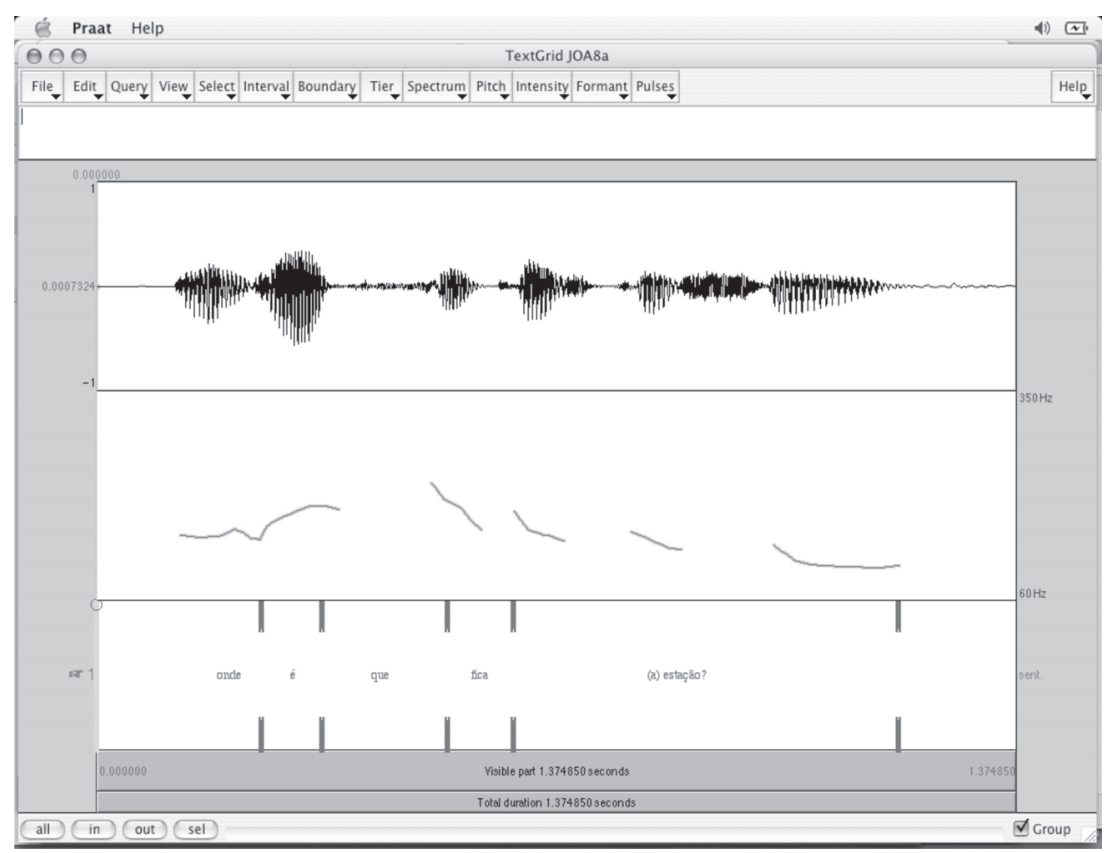

GRÁFICO 7 - Pergunta Wh- no PB. Exemplo 3.:"Onde é que fica a estação?”

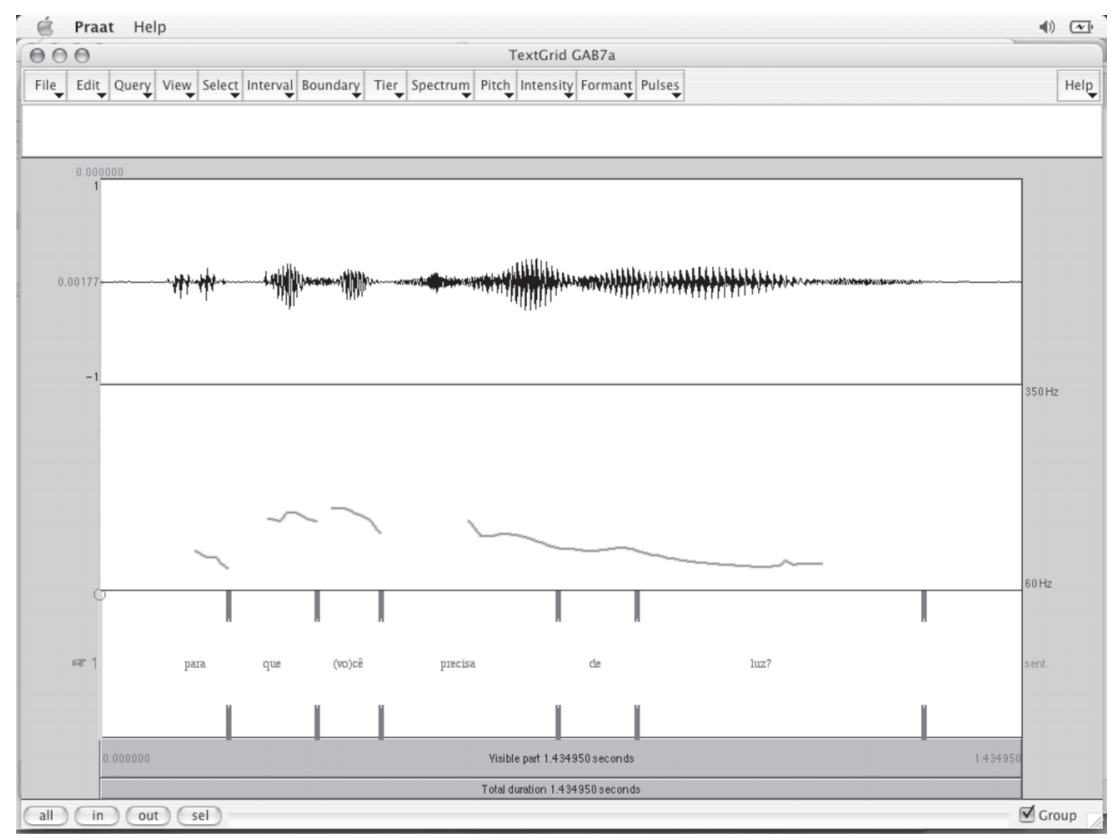

GRÁFICO 8 - Pergunta Wh- no PB. Exemplo 4. "Para que você precisa de luz?" 
ReinecKe, K. ParÂmetros Acústicos de Perguntas Sim-Não e Wh...

No AL, continua a predominar o padrão com duas elevações entoacionais, isso ocorrendo em onze dos doze casos. Porém, diferentemente do padrão do pitch nas perguntas sim-não, nas perguntas Wh-, a segunda elevação também termina em um movimento entoacional descente. A última sílaba da sentença não é mais a mais elevada. O pico do pitch pode ocorrer tanto em uma das duas primeiras, quanto em uma das três últimas sílabas. Vejamos os exemplos 5 e 6.

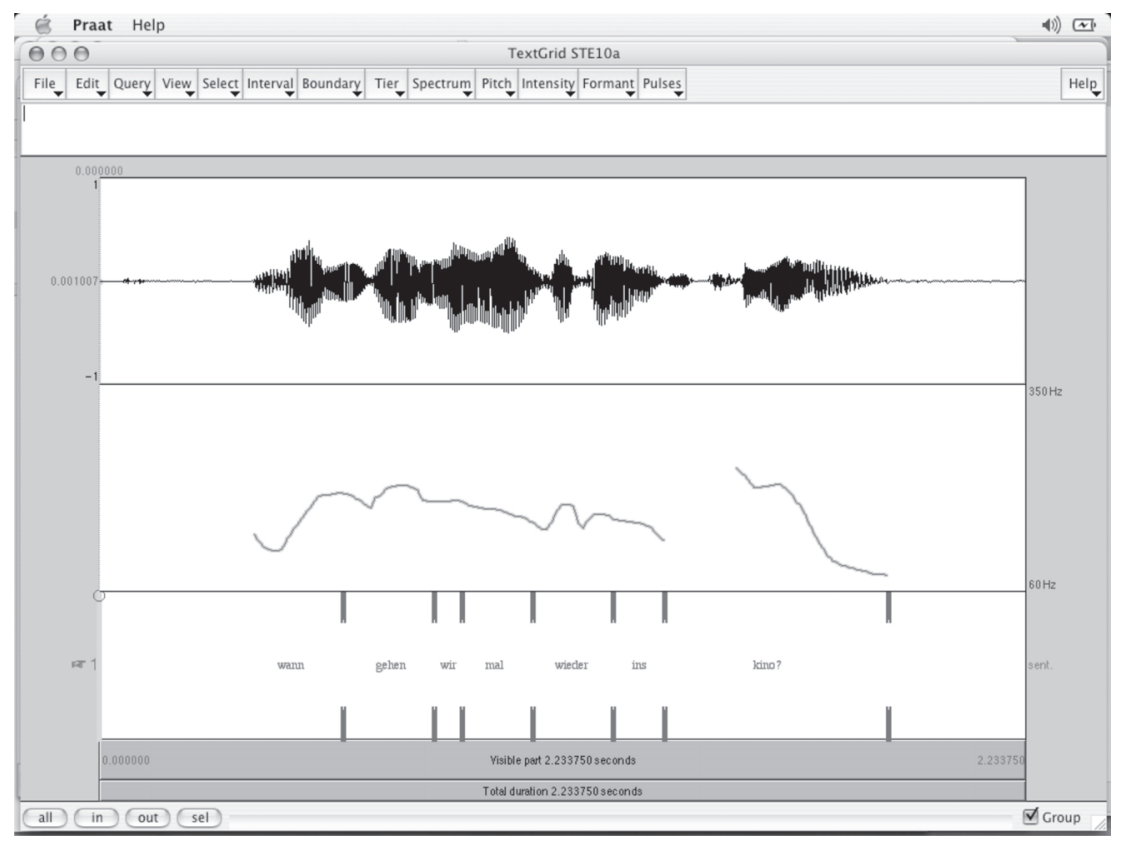

GRÁFICO 9. Pergunta Wh- no AL. Exemplo 5.:"Wann gehen wir mal wieder ins Kino?" 


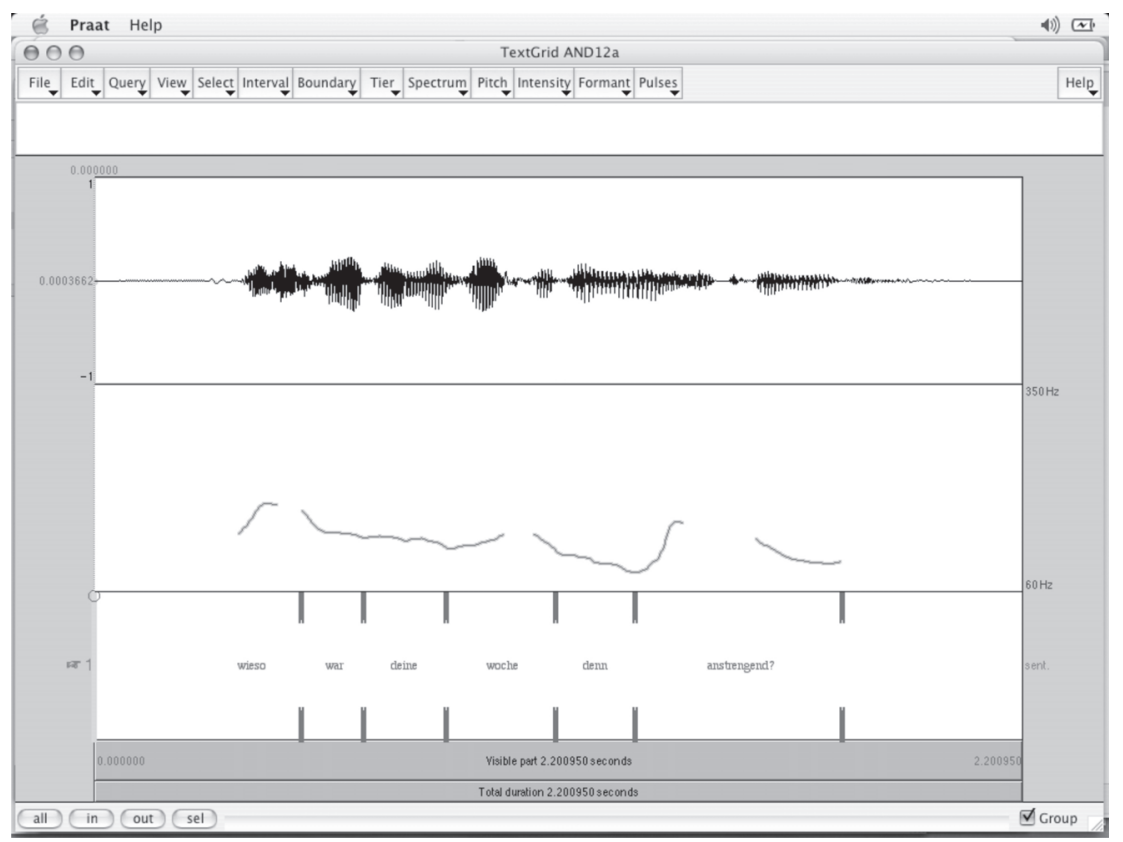

GRÁFICO 10 - Pergunta Wh- no AL. Exemplo 6.:"Wieso war deine Woche denn anstrengend?"

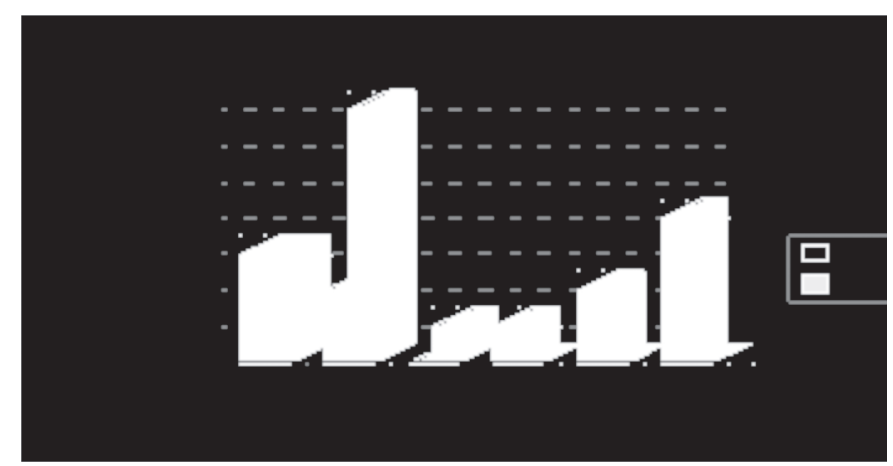

GRÁFICO 11 - Perguntas Wh- no AL e no PB: maiores picos de pitch

No parâmetro intensidade, observamos duas tendências interessantes. Por um lado, nas perguntas Wh- se repete um fenômeno que já observamos nas perguntas sim-não: ambas as línguas permitem uma grande variação na sílaba que carrega o máximo de intensidade. São seis, no AL, e sete, no PB, as variações possíveis em cada idioma. Apesar dessa distribuição ampla, e em contrário ao que observamos nas perguntas sim- 
REINECKE, K. ParÂmetros Acústicos de Perguntas Sim-Não E WH.

não, tanto no $\mathrm{AL}$, quanto no $\mathrm{PB}$, observa-se uma forte tendência da segunda sílaba atrair o pico de intensidade. Isto ocorreu nas duas línguas em metade dos exemplos. Levando em consideração que o parâmetro intensidade é altamente suscetível a variações por causas externas, como, por exemplo, a distância entre o falante e o microfone, temos que interpretar esses dados com cautela ${ }^{10}$. Não obstante, acreditamos que seja possível detectar, pelo menos, uma tendência aqui. No caso das perguntas sim-não, já observamos que, no AL, as primeiras 3 sílabas são que carregam a máxima de intensidade. Agora nas perguntas Wh- vemos uma certa tendência na mesma direção, desta vez em ambas as línguas.

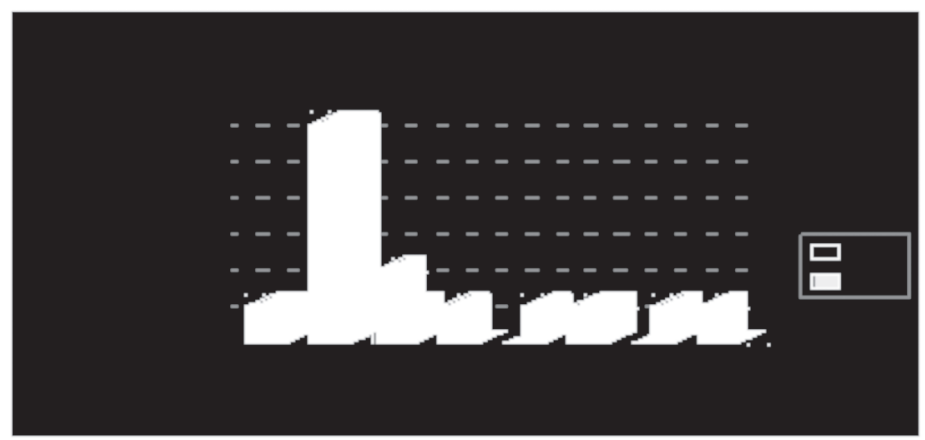

GRÁFICO 12 - Perguntas Wh- no AL e no PB: os valores máximos de intensidade

Vejamos em seguida, a distribuição da maior duração nas perguntas \#Wh-.

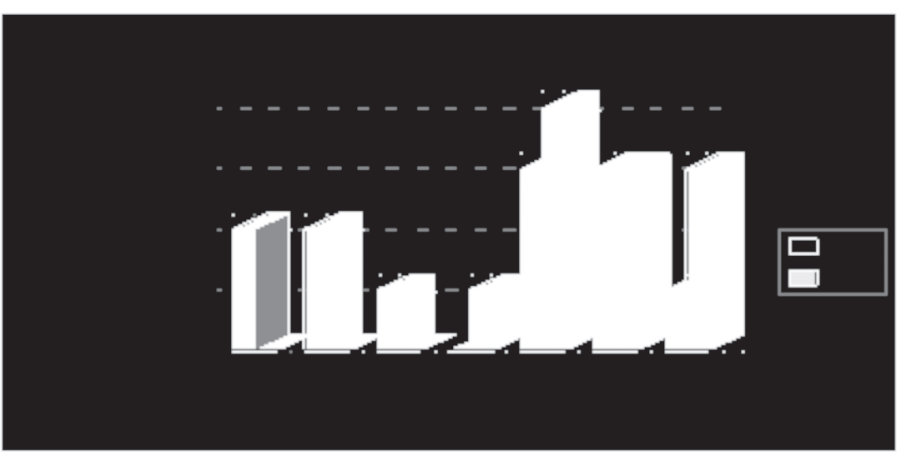

GRÁFICO 13 - Perguntas Wh- no AL e no PB: valores máximos de duração

10 Agradeço, nesta altura, ao avaliador anônimo pela observação. 
Aqui observamos que o padrão nas perguntas Wh- se parece muito com o padrão das perguntas sim-não. No $\mathrm{PB}$, com uma exceção, a sílaba com a maior duração é sempre uma das últimas três. No AL, a duração maior pode coincidir com seis posições silábicas diferentes (nas perguntas simnão são sete posições). O AL parece ter uma leve tendência a favor em uma das últimas três sílabas, mas em cinco de doze exemplos, a sílaba com a maior duração foi uma das três primeiras. Resta observar se não há duração maior no meio da sentença. Possíveis motivos para essa distribuição, veremos na seção seguinte.

\subsection{INTERPRETAÇÃo FUnCIONAL: INFLUÊNCIAS SinTÁticAS, PRAGMÁTICAS E FONOLÓGICAS}

\subsubsection{Perguntas Sim-NÃo}

Já vimos que, no AL, nas perguntas sim-não, o verbo ocupa necessariamente a primeira posição sintática, seguido obrigatoriamente pelo sujeito gramatical. O gráfico 14 nos mostra quais constituintes sintáticos podem ser identificados como coincidentes com as saliências acústicas realizadas pelos informantes.

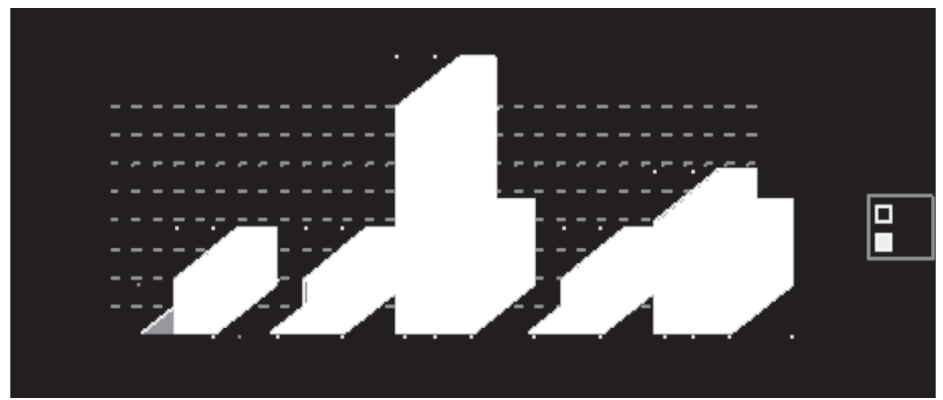

GRÁFICO 14 - Constituintes sintáticos salientados pelo pitch no AL e no PB

Lembremos que, no AL, o pico do pitch recai em 100\% dos exemplos na última sílaba da sentença. Em $75 \%$ dos casos, essa posição está ocupada pelo objeto gramatical da sentença, em $25 \%$ dos casos, por outro constituinte sintático. Porém, é preciso lembrar que o pico do pitch não recai sobre as sílabas tônicas desses constituintes, e sim, sempre sobre a última sílaba da sentença. Esta, em oito casos, é uma sílaba átona, e em quatro casos, uma tônica.

Comparemos agora os resultados com os do PB. No PB, nas perguntas sim-não, o pico do pitch salienta ou a segunda, ou a terceira, ou uma das últimas três sílabas da sentença. Essas sílabas coincidem, no 
material gravado, em dois casos com o verbo, em dois casos com o sujeito gramatical, em três casos com o objeto gramatical, em dois casos com constituintes adverbiais "clivadas", e em três com outros tipos de constituintes sintáticos. É importante mencionar que, em um dos dois informantes, o pico do pitch recai em cinco de seis casos sobre uma das três últimas sílabas, ou seja, a última sílaba tônica da sentença, enquanto, no outro informante, isto acontece só uma vez. E, ao contrário, o segundo informante, em cinco de seis casos, salienta um constituinte sintático no começo da sentença através do pico do pitch. Olhando a sílaba que carrega o segundo maior pico do pitch, observa-se que ambos os informantes o atribuem ao constituinte, ao qual o outro atribui o primeiro maior pitch. (Em dez dos doze exemplos há duas elevações do pitch). 0 informante que atribui o primeiro pico do pitch a uma das três últimas sílabas atribui o segundo maior pitch ao verbo. $O$ informante que atribui o primeiro pico do pitch às posições de verbo, sujeito ou objeto atribui o segundo maior pitch a uma das últimas três sílabas. Ou seja, os constituintes sintáticos e as posições silábicas salientadas pelo pitch são parecidos em ambos os informantes, só que a prioridade é trocada entre os dois. Os gráficos 15 e 16 ilustram a descrição.

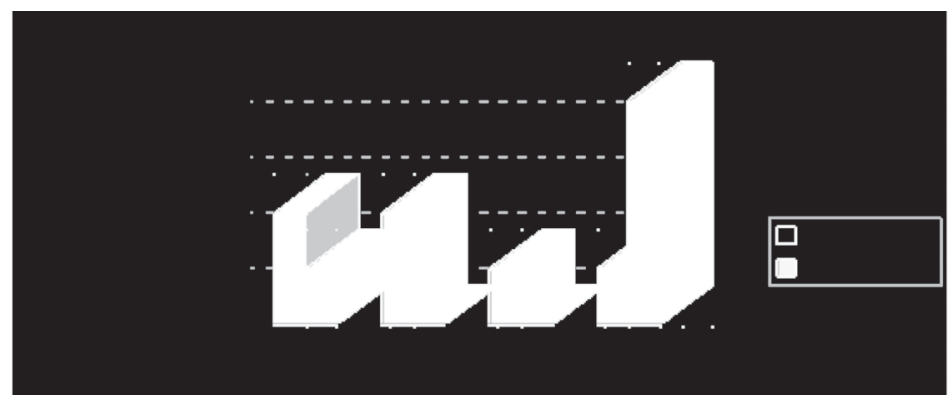

GRÁFICO 15 - Perguntas sim-não no PB: constituintes sintáticos salientados através do primeiro e do segundo pico de pitch, informante 1

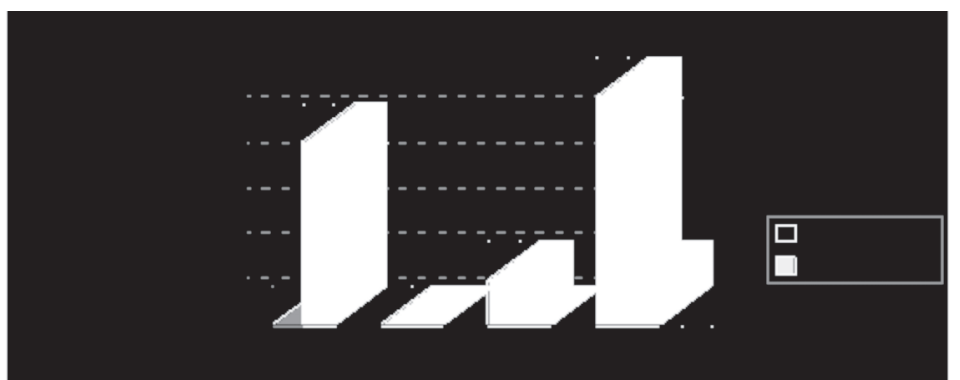

GRÁFICO 16 - Perguntas sim-não no PB: constituintes sintáticos salientados através do primeiro e do segundo pico de pitch, informante 2 
Nos gráficos 15 e 16, encontramos uma categoria que não é sintaticamente bem definida. É a "outro / tônica". Essa categoria mostra a dificuldade de classificar sintaticamente um total de seis casos com o primeiro pico de pitch, e cinco casos no segundo pico de pitch no PB. Esta dificuldade pode ser interpretada como indicadora de uma regra fonológica que age sobre as regras sintáticas. A regra poderia ser: Salientar através do pitch a sílaba tônica da última frase fonológica. Nessa posição, fonologicamente definida, encontram-se, nas sentenças gravadas, os objetos, direto e indireto, e um adjetivo em posição de predicado. Chegamos então à conclusão de que, tanto no AL quanto no PB, uma classificação meramente sintática não consegue refletir bem as regras que aparentemente agem sobre a distribuição das saliências. Portanto, tentaremos formular uma classificação conjunta dos critérios sintáticos, fonológicos e pragmáticos. O aspecto pragmático também é incluído, porque veremos ainda que, no AL, entre as saliências formadas através do segundo pico do pitch, da intensidade e da duração, há constituintes que parecem receber uma ênfase não-neutra de um dos informantes. No quadro 2, encontramos todas as interpretações já discutidas e, dentro de uma tabela, os três parâmetros acústicos em comparação. Avaliaremos primeiro o caso do AL nas perguntas sim-não.

\begin{tabular}{|l|c|c|c|c|c|c|}
\hline \multicolumn{1}{|c|}{ constituinte $\Rightarrow$} & \multicolumn{3}{c|}{ sintático } & pragmático & \multicolumn{2}{c|}{ fonológico } \\
\hline meio acústico $\downarrow$ & verbo & sujeito & partícula & ênfase & última tônica & última sílaba \\
\hline 1o. pitch & & & & & $\left(4^{11}\right)$ & 12 \\
\hline 2o. pitch & 8 & & & 2 & & \\
\hline pico intensid. & 5 & 1 & 2 & 4 & & \\
\hline pico duração & 2 & & & 4 & 7 & \\
\hline
\end{tabular}

QUADRO 2 - As três saliências acústicas e os três âmbitos linguísticos analisados no AL nas perguntas sim-não

Comparando o primeiro e o segundo picos de pitch, observamos uma diferença funcional bem nítida. O ponto entoacional mais alto de todas as sentenças está ligado exclusivamente à sinalização do modo sentencial. o segundo pico mais alto, ao contrário, salienta normalmente um constituinte sintático, ou seja, nos casos observados, o verbo. Um só meio acústico é aproveitado para cumprir duas funções diferentes. Quando entra alguma ênfase especial, como nos dois casos discutidos em 5.2.1, o pitch também cumpre uma função diferente das demais. Na intensidade, observamos como tendência mais nítida que ela nunca coincide com a última sílaba tônica ou a última sílaba da sentença. Entre os constituintes sintáticos e os casos de ênfase pragmática, porém, não há uma tendência tão nítida. Através da 
Reinecke, K. Parâmetros Acústicos de Perguntas Sim-Não E Wh...

intensidade, os informantes salientam constituintes sintáticos diferentes. Nos casos da ênfase pragmática, ela parece puxar o pico da intensidade para ela. Enquanto, no caso do segundo maior pico de pitch, a ênfase pragmática atrai a saliência só em dois dos quatro casos. 0 pico de intensidade coincide em todos os quatro casos com a sílaba enfatizada pragmaticamente. $O$ parâmetro intensidade parece estar livre para cumprir ou uma função sintática ou uma função pragmática, dependendo talvez da atribuição dos outros meios acústicos nas saliências de cada sentença.

Somando os picos de duração, a linha resulta em treze ocorrências em vez de doze, porque, em um caso, havia duas sílabas com exatamente a mesma duração, uma em função da saliência da última sílaba tônica, a outra em função da ênfase pragmática. A tendência da duração parece ser de coincidir com a última sílaba tônica, ou seja, salientar o último sintagma fonológico.

Compararemos os resultados encontrados para o $\mathrm{AL}$, com os resultados para o $\mathrm{PB}$, através do Quadro 3:.

\begin{tabular}{|l|c|c|c|c|c|c|}
\hline \multicolumn{1}{|c|}{ constituinte $\Rightarrow$} & \multicolumn{3}{c|}{ sintático } & pragmático & \multicolumn{2}{c|}{ fonológico } \\
\hline meio acústico $\Downarrow$ & verbo & sujeito & clivagem & ênfase & última tônica & últ. síl. \\
\hline 1o. pitch & 2 & 2 & 2 & & 6 & $\left(4^{12}\right)$ \\
\hline 2o. pitch & 6 & & & & 4 & \\
\hline pico intensidade & 7 & 2 & & & 3 & \\
\hline pico duração & & 2 & & & 10 & \\
\hline
\end{tabular}

QUADRO 3 - As três saliências acústicas e os três âmbitos linguísticos analisados no $\mathrm{PB}$ nas perguntas sim-não

No PB, não há exemplos de ênfase pragmática. Tampouco se salienta uma partícula, mas há duas sentenças, em que acontece um tipo de clivagem de constituintes sintáticos (adverbiais). Outra diferença, para o AL, é que a última sílaba da sentença nunca é salientada por si só. Para a Fo, lembremos, primeiro, que, no caso do pico do pitch, ambos os informantes aplicaram um padrão diferente. Um atribui o maior pico do pitch quase sempre à última sílaba tônica, o outro quase sempre ao verbo ou ao sujeito e, no caso do constituinte clivado, ambos os informantes atribuem o pico do pitch a ele. A sentença em questão é "Na SEXta você pode ver o filme?". A sílaba em maiúsculas indica o pitch máximo. Essa saliência pode ser interpretada de duas maneiras: Ou ela se encaixa na tendência de a segunda (ou terceira) sílaba carregar o maior pico de pitch, como observamos em $50 \%$ dos casos do PB (essa seria uma outra explicação fonológica); ou ela é salientada justamente por ser um constituinte clivado, ou seja, sua saliência é motivada por um fator sintático-pragmático. A 
segunda interpretação parece ser mais provável, se olharmos para o comportamento diferente dos dois informantes. No maior pico de pitch, um mostra a tendência de salientar quase sempre a segunda ou a terceira sílaba, o outro, quase sempre a última tônica. No entanto, os dois salientam a segunda sílaba na sentença discutida. Também o informante que não segue a regra "sempre segunda ou terceira", atribui o pico de pitch nesse lugar da sentença onde acontece a clivagem. Deduzimos que já haja uma tendência para salientar essa posição no $\mathrm{PB}$, e que a clivagem tem ainda uma mais forte influência de atrair o maior pico de pitch.

O segundo maior pico do pitch, no $\mathrm{PB}$, pode ser atribuído tanto ao verbo, quanto à última sílaba tônica, portanto aqui observamos uma tendência parecida com a do AL. Esse meio acústico não parece ser reservado para cumprir uma só função na realização da sentença, mas pode variar nessas funções. A intensidade varia menos no PB, do que no AL. Ou ela coincide com um dos dois constituintes sintáticos, o verbo, de preferência, ou o sujeito; ou ela coincide com a última sílaba tônica.

Olhando, por último, a duração, descobrimos que ela se encaixa em uma tendência geral de todos os parâmetros nas perguntas sim-não no PB: a de salientar a última sílaba tônica. No AL, a duração é o único parâmetro conectado com essa função, enquanto, no $\mathrm{PB}$, a duração é o primeiro parâmetro, dentre outros.

\subsubsection{Perguntas Wh-}

Nas perguntas Wh-, no AL, o pronome interrogativo ocupa a primeira posição, seguido obrigatoriamente pelo verbo em segunda posição e o pronome pessoal na terceira posição. No PB, essa ordem, "pronome interrogativo+verbo" também é possível, porém, quando houver sujeito gramatical, ele normalmente entra antes do verbo.

\begin{tabular}{|l|c|c|c|c|c|}
\hline \multicolumn{1}{|c|}{ constituinte } & \multicolumn{2}{c|}{ sintático } & pragm. & \multicolumn{2}{c|}{ fonológico } \\
\hline meio acústico & pron. interrogat. & verbo & & última tônica & última sílaba \\
\hline $1^{\circ}$. pitch & 3 & 2 & & 5 & 2 \\
\hline $2^{\circ}$. pitch & 6 & 1 & & 4 & $(2)$ \\
\hline pico intens. & 3 & 6 & & & outros: 3 \\
\hline pico duração & 2 & 3 & & 7 & \\
\hline
\end{tabular}

QUADRO 4 - As três saliências acústicas e os três âmbitos linguísticos analisados no AL nas perguntas Wh-

No caso de maior pico de pitch, nas perguntas Wh-, no AL, há dois exemplos (contados como "pronome interrogativo") em que a curva entoacional chega no seu pico na divisa entre o pronome interrogativo e o verbo. Em geral, o maior pico de pitch pode ocorrer na posição do verbo, na 
Reinecke, K. Parâmetros Acústicos de Perguntas Sim-Não E Wh...

última sílaba tônica e na última sílaba. Para perguntas Wh-, no AL, normalmente não se reporta uma saliência entoacional da última sílaba. Em nosso caso, esse fenômeno pode ocorrer devido às gravações das perguntas sim-não, que foram realizadas antes das Wh-. Os informantes talvez tenham sidos influenciados pelo padrão de interrogativas sim-não. Porém, a curva entoacional realizada, nos exemplos respectivos, pode ser julgada como natural. Indicando assim que o padrão aplicado faz parte das possíveis escolhas entoacionais também nas perguntas Wh-.

O segundo maior pico de pitch mostra um comportamento bem parecido com o do primeiro pico de pitch. Assim, quando o primeiro pico salienta um constituinte no começo da sentença, o pronome interrogativo ou o verbo; o segundo salienta a tônica e / ou a última sílaba. E vice-versa.

$\mathrm{Na}$ intensidade, em três casos, não se identifica nenhum padrão regular. Nos outros casos, há uma tendência em salientar o verbo antes do que o pronome interrogativo. A duração se comporta de maneira parecida como já observamos nas perguntas sim-não. Ela tem uma tendência de recair sobre a última tônica, porém, em cinco casos é atribuída ao verbo ou ao pronome interrogativo, indicando que haja dois padrões agindo paralelamente. Vejamos então o caso do PB, a partir do Quadro 5.

\begin{tabular}{|l|c|c|c|c|}
\hline \multicolumn{1}{|c|}{ item: } & \multicolumn{2}{r|}{ sintático } & pragmático & fonológico \\
\hline meio acústico & $\begin{array}{l}\text { pronome } \\
\text { interrog. }\end{array}$ & verbo & & última tônica \\
\hline 1o. pitch & 8 & 3 & & \\
\hline pico intensidade & 5 & 5 & & 1 \\
\hline pico duração & & 1 & & 10 \\
\hline
\end{tabular}

QUADRO 5 - As três saliências acústicas e os três âmbitos linguísticos analisados no $\mathrm{PB}$ nas perguntas Wh-

O que chama a atenção em primeiro lugar, ao comparar os resultados do $\mathrm{PB}$ com os do AL, é que a própria tabela do $\mathrm{PB}$ é menor do que as das perguntas sim-não, e menor do que a do AL nas perguntas Whtambém. Isto se deve aos seguintes fatores: no $\mathrm{PB}$, não se realiza uma segunda elevação de pitch nas perguntas Wh-. O mais interessante é que as funções dos meios acústicos no PB, nas perguntas Wh-, parecem ser mais bem definidas e limitadas. Observamos que tanto o pitch quanto a intensidade servem, exclusivamente, com exceção da intensidade, para salientar um constituinte sintático, ou seja, o verbo ou o pronome interrogativo. Como o maior pico de do pitch recai sempre em uma das primeiras três sílabas da sentença, pode se seguir também a analise de Moraes (1998) que consta que, nas perguntas Wh-, o pico do pitch recai sobre a primeira sílaba tônica 
da sentença. Através da duração, como já observamos antes, é salientada a última sílaba tônica.

Por último, vale a pena acrescentar que, nas perguntas Wh-, em ambas as línguas, se observa um fenômeno distinto do das perguntas simnão. No caso do pitch, e também da intensidade, observam-se cerca sete casos em que o próprio pico desses parâmetros recai sobre mais do que uma sílaba da sentença. No AL, cria-se assim a impressão de que o pico é alcançado entre o pronome interrogativo e o verbo, enquanto, no PB, parece que o pico se estende ainda mais, do pronome interrogativo até duas ou três sílabas depois.

\section{CONCLUSÃO}

Os resultados discutidos até agora parecem refletir padrões prosódicos subjacentes. Os três meios acústicos analisados estão associados a diferentes funções linguísticas, sem que haja uma relação biunívoca entre eles. O valor máximo de duração, em ambas as línguas, co-ocorre fortemente com a sílaba acentuada do último grupo fonológico das sentenças examinadas. Essa tendência se observa mais nitidamente no PB do que no AL. A intensidade, tanto no $\mathrm{PB}$, quanto no $\mathrm{AL}$, tem um comportamento menos regular, ela parece ser conectada a diferentes funções linguísticas. Dentro deste experimento, não foi possível destacar uma delas como principal, ou mais importante. O pico de pitch, no AL, nas perguntas sim-não é o meio mais diretamente associado à sinalização do modo. Nas perguntas Wh-, já não há um funcionamento tão regular. No $\mathrm{PB}$, é o contrário: um padrão mais claro nas perguntas Wh-, e resultados mais diversos nas perguntas sim-não.

Comparando os resultados discutidos aqui com os de Moraes (1998) e Stock (1996), vemos primeiro que, no caso do PB, Moraes afirma que a elevação do pitch nas perguntas sim-não acontece na última sílaba tônica. Nos resultados desta pesquisa, este é o caso de somente $50 \%$ dos dados. A outra metade tem o seu pico de pitch em uma das primeiras sílabas. Um padrão destacado pelo Moraes, o movimento entoacional de duas elevações, em nossos dados se encontra como principal padrão nas perguntas simnão. Como Moraes qualifica esse padrão como abertura de um diálogo, pode valer a pena pesquisar mais profundamente o status informacional da sentença realizada com esse padrão entoacional. A diferença entre os nossos dados e o que explica o Moraes, é que para ele, a primeira elevação é maior do que a segunda. Em nossos dados, em $50 \%$ dos casos, a segunda elevação é a maior das duas. Para as perguntas Wh-, Moraes constata que a elevação 
ReinecKe, K. ParÂmetros Acústicos de Perguntas Sim-Não e Wh...

do pitch acontece na primeira sílaba tônica. Isto se confirma nos dados analisados. Parece não haver diferença, se esta posição está ocupada pelo verbo, pelo pronome interrogativo, ou, como em dois casos, por um constituinte clivado.

Para o AL, observamos que o Stock afirma que a necessidade de aplicar um padrão entoacional diminui dependendo do grau em que a sintaxe sinaliza inequivocadamente a estrutura interrogativa. Porém, em nossos dados, as perguntas sim-não, todas com a inversão sintática obrigatória realizada, são acompanhadas pelo padrão entoacional da ascensão na última sílaba. A prosódia de leitura parece ser mais conservadora neste caso, do que as possibilidades da fala espontânea como consta Stock.

\title{
RESUMO
}

Baseado na definição de prosódia e entoação de Hirst e di Cristo (1998), neste trabalho se analisa a contribuição e a interdependência dos três parâmetros FO, duração e intensidade nos padrões prosódicos interrogativos, em seu lado formal e funcional. Nas duas línguas em comparação, o português brasileiro e o alemão, a FO se revela o fator mais diretamente ligado à sinalização do modo. A duração parece exercer, em primeiro lugar, a função de agrupamento e de salientar a sílaba tônica do último grupo fonológico de cada sentença. A intensidade não mostra um comportamento muito regular em nenhuma das duas línguas e parece estar conectada a mais do que uma função linguística. Para o alemão, os dados confirmam um padrão descrito na literatura no caso das perguntas sim-não: O maior pico da curva entoacional recai regularmente sobre a última sílaba da sentença, seja ela tônica ou átona. Para o português brasileiro, não foi detectado um padrão tão claro para as perguntas sim-não.

Palavras-chave: Entoação; Interrogativa; Fonética Acústica.

\begin{abstract}
Based on the definition of prosody and intonation by Hirst and di Cristo (1998), we analyze the interdependency and the role of three acoustic parameters, e.g. FO, duration and intensity in signalizing question patterns. Comparing German and Brazilian Portuguese, we discuss formal and functional aspects of the three parameters. In both languages, Fo turns out to be the factor most closely related to the interrogative modus. Duration seems to be connected, in the first place, in
\end{abstract}


functions of grouping and giving prominence to the stressed syllable in the phonological group of every sentence. Concerning intensity, there is no such thing as a regular behaviour in any of the languages in question, but the parameter does fulfil several linguistic functions. In German, the data affirms patterns previously described for the yes-no question: The major pitch is realized on the very last syllable of the sentence, no matter whether it is stressed or not. In Brazilian Portuguese, no such strong pattern is detected for yes-no questions.

Keywords: Intonation; Interrogation; Acoustic Phonetics.

\section{REFERÊNCIAS}

BOERSMA, Paul; WEENINK, David. Praat: Doing Phonetics by Computer. (Version 4.3.04) [Programa de computador] Disponível em: <http://www.praat.org/>. Acesso em: 12/07/ 2009.

ROBINSON, John; LAWRENCE, Helen; TAGLIAMONTE, Sali. GoldVarb 2001: A multivariate analysis application for Windows. Disponiìvel em: <http://www.unh.edu/linguistics/ index.cfm?id=2A51E02A-D856-146A-768D34E4DD28644A>. Acesso em: 12/07/2009.

HIRST, Daniel; DI CRISTO, Albert (Ed.). Intonation systems: a survey of twenty languages. Cambridge: CUP, 1998.

LADD, Dwight Robert. Intonational Phonology. Cambridge: CUP, 1996.

MADDIESON, Ian. Phonetic Universals. In: HARDCASTLE, William J.; LAVER, John. (Ed.) The Handbook of Phonetic Science. Oxford, Cambridge (Mass.): Oxford University Press, 1997, cap. 20, p. 619-639.

MORAES, João Antônio. Intonation in Brazilian Portuguese. In: HIRST, Daniel; DI CRISTO, Albert (Ed.). Intonation Systems: a survey of twenty languages. Cambridge: CUP, 1998. p. 179-194.

STOcK, Eberhard. Deutsche Intonation. Berlin, München, Leipzig: Langenscheidt, 1996.

Submetido em: 19/08/2007.

Aceito em: 07/07/2009. 